\title{
Community Based Medical Education - Necessity Realization and Practice
}

\author{
Koju R \\ Dhulikhel Hospital \\ Kathmandu University Hospital, Dhulikhel, Kavre, Nepal
}

Health care delivery is vastly diverse worldwide. This is more unequal in low and middle-income countries like Nepal. Hospitals equipped with advanced diagnostic means and qualified medical doctors are abundantly available in urban areas whereas remote peripheral villages are suffering from dearth of infrastructure and medical doctors. Although the system has always tried to distribute infrastructure and human resources equally to remote urban areas according to necessity, the reality is different than what it is expected to be.

With regards to health care in underserved areas physical infrastructures and equipments are not as challenging as the issue of human resources. Whereas financial constraint is the major issue in terms of physical infrastructures and equipments, human resources tend to be more complex because of numerous reasons like, incentives, family support, motivation to work, etc. Since will of a person is the biggest impetus for his/her performance, it is essential to understand that identifying ways to motivate people would be the mainstay of solution in relation to human resources in health as well.

Realization of needs and motivation can be aroused during their earlier phase of professional development as a medical student. All the stakeholders in health and health sciences education (universities, health service providers, professional councils, individual colleges, civil societies and community based institutions, etc.) can play a major role in developing a system where the future health professionals develop insights in rural health care delivery and also get motivated to participate in contributing to the same. In the Nepalese context, although all academic institutions have some sort of component of community-based curriculum and community based learning (CBL), there are still huge differences in practices.

The medical colleges and hospitals providing tertiary level health care can also be of important resources for the development of primary level health sector of Nepal. Right from the initiation of the first medical college, medical education program was supposed to be community based and it managed to be so to some extent. With the rapid increase of medical institutions in the country, it is important to have clear analysis of the current impact of the medical colleges in the primary level health sector of the country through community based learning (CBL) approaches of the colleges.

In a recent study of eight medical colleges in the country, it was found that there were poor orientation or guidelines to the students about CBL, e.g.,field posting, poor supervision, varied location and duration of the field program as per the colleges. ${ }^{1}$ In the study, it was also found that with good supervision, guidelines and long residence in remote communities, the students have very good experience of CBL. When students have little supervision, guidelines, short residence in local communities, they feel that it not only is a poor experience but also in many respects deteriorate the relationship with the communities and the local government staffs. The communities and the local government staffs also voiced similar concern.

There are significant opportunities for students to learn from CBL. This can increase their knowledge, skills, management and leadership quality for the motivation to work in community. Study conducted in these college of Nepal, showed that more than half of the students agreed that CBL had changed the approach they dealt with patients. Forty percent students expressed their agreement to the statement that CBL would change their career plan. ${ }^{1}$ The communities are benefitted mainly through health education offered by the students. The program can create a win-win situation in between medical college and government through training, lectures, referral system, camps, and specialized visit to the health centers. Three fourth of the primary health sector staff agreed that $\mathrm{CBL}$ has positive impact in the health center.

Despite the opportunities, the main challenge identified was lack of clear guidelines and policy for the program. The other challenges identified were lack of interest of college, faculties and students; accommodation and logistic problem of the college; high expectation and low response of the community; expectation from government staff; poor supervision and preparation of the students; duplication of the field area; and student's poor attitude. 
It is thus very important to have clear guidelines from policy level defining the roles and responsibilities of respective institutions. This should be further strengthened by a robust monitoring and evaluation mechanism. There is very strong need for an early discourse between the national level stakeholders of medical education and health care services in terms of CBL strategies in medical education. The environment is very conducive to develop clear guidelines and policies in this issue. A success in this would mean not only a benefit in health services to the people in underserved areas, but also a production of better informed and motivated medical graduates who can be instrumental in changing the future of health services in the country.

\section{REFERENCES}

1. Koju R, Karmacharya B, Shrestha S, Shrestha S, Shakya P, Marahatta SB. Impact, opportunities and challenges of the community based learning (CBL) programs of Nepalese medical colleges in the development of primary health care sector of Nepal [University Granted research]. Dhulikhel, Nepal: Kathmandu University School of Medical Sciences; 2011 (Unpublished data). 